\section{Facing the music with orthodontics}

The British Orthodontic Society (BOS) has published an advice sheet for young musicians who play wind instruments and are due to have orthodontic treatment.

The advice explains what can be expected while wearing a brace and suggests some ways of coping with possible problems. The good news is that, with practice and motivation, most wind instrument players can adjust to wearing braces.

'Some musicians may find that orthodontic treatment affects their ability to practice and perform. However, the effect on musical performance is likely to be temporary only and musicians will get used to the braces within a few months,' said David Morris, Chairman of the Clinical Standards Committee of BOS.

Orthodontic patients are, however, advised to have their braces fitted during a period when they are not taking important music exams or going for auditions. Those who play the trumpet or trombone

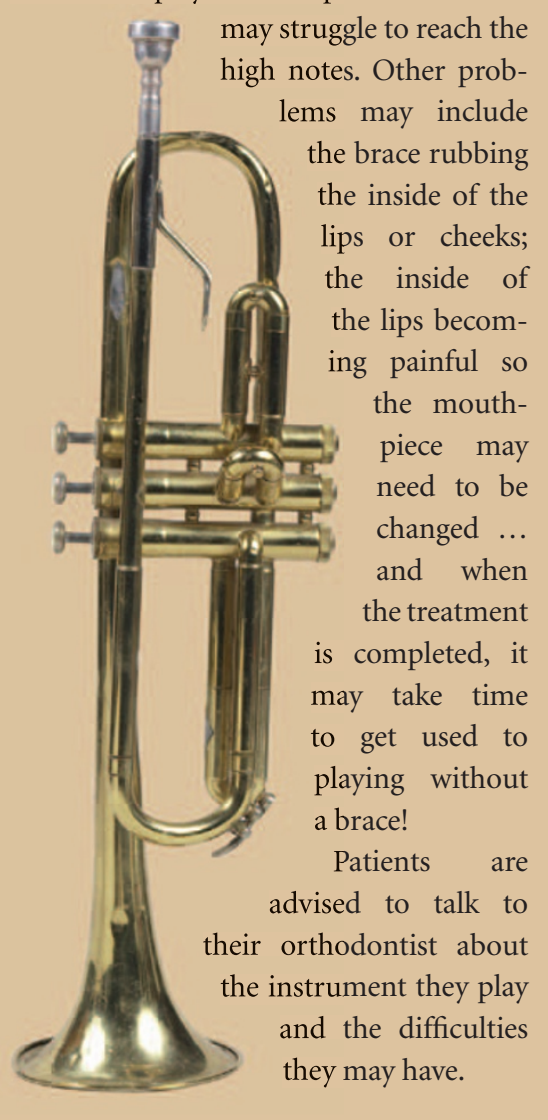

\title{
Milk and cheese, please
}

The Dairy Council has launched an educational campaign called 'Slurp and chew your way to dental health', designed to inform the public about the benefits of milk and cheese on dental health.

'We are very excited about this campaign,' said Dr Judith Bryans, Director of the Dairy Council. 'These dairy products contain calcium and phosphorus, which are important for the growth, development and health of teeth. Milk is one of the few drinks that are safe to have between meals, and a small piece of hard cheese chewed on its own after meals can actually help reduce the risk of tooth decay.'

The campaign kicked off on 11 February this year with a 30 second spot airing in at least 160 dental surgeries across the UK, and will reach an estimated audience of over 1.3 million during 2008.

The 30 second clip can be viewed at www. milk.co.uk. Further information relating to dairy research and nutrition advice relating to dairy can also be found at this site or by contacting The Dairy Council on info@ dairycouncil.org.uk or on 02073954030.

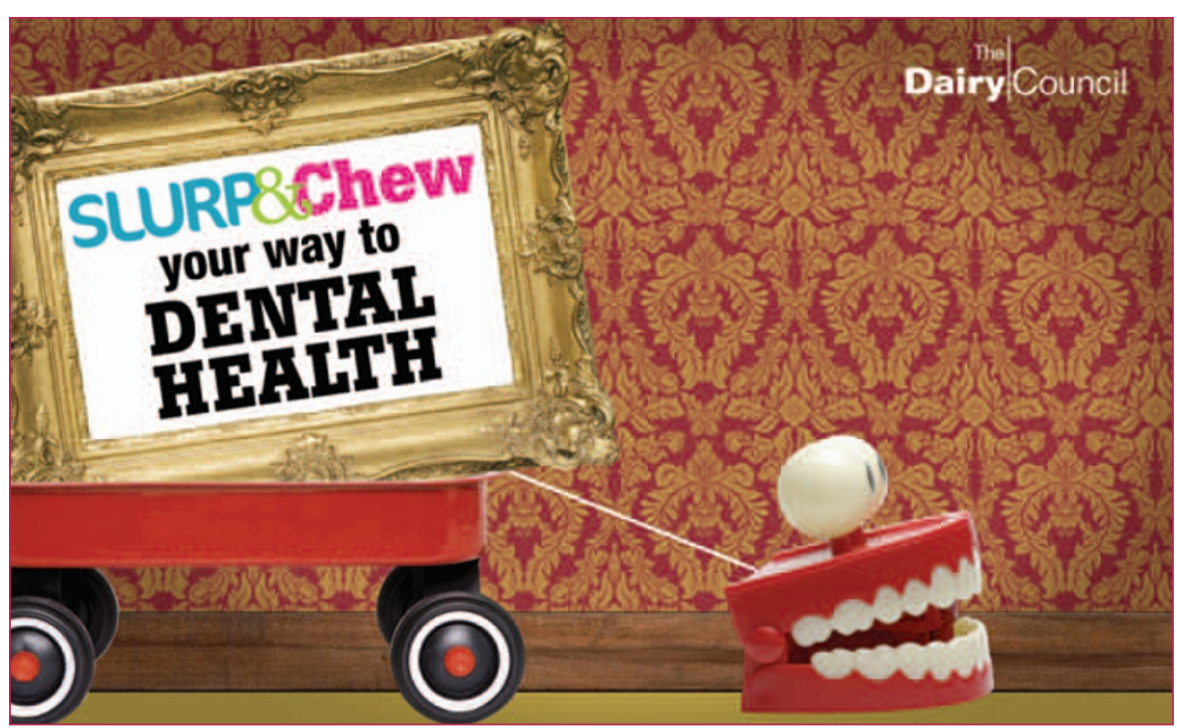
\section{Time for teams} The theme for this year's British Dental Conference \& Exhibition is 'Strategies for success: you and your team'.

The event will be held at Manchester Central Convention Complex from 1-3 May 2008 and promises to be the biggest to date, and perhaps the most team-focused.

DCP sessions will include: 'Preparing for DCP registration'; 'Strategies for successful teamwork' (by President of the BADT, Leigh Ann Randell); 'Now you are a registered professional - compulsory CPD for DCPs'; 'Are you an expansive receptionist or a cheap practice manager' (hosted by the BDPMA); and 'The dental nurse's guide to clinical governance', led by Pam Swain and Angie McBain from BADN.

Registrations for the conference must be received by Thursday 24 April 2008 in order to receive your badge and joining instructions

\section{in Manchester}

in advance of the event. Team discounts are available and online registrations also receive a discount off conference ticket bookings. To book your place, go to www.bda.org/events or telephone 08701666625.

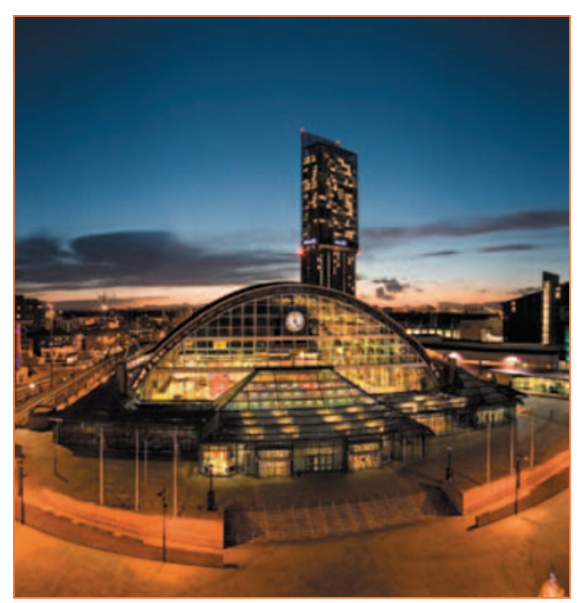

